\title{
PERFORMANCE ANALYSIS OF MULTIPURPOSE REFRIGERATION SYSTEM (MRS) ON FISHING VESSEL
}

\author{
Y. Ust, \\ A. Sinan Karakurt, \\ U. Gunes, \\ Yildiz Technical University, Turkey
}

\begin{abstract}
The use of efficient refrigerator/freezers helps considerably to reduce the amount of the emitted greenhouse gas. A two-circuit refrigerator-freezer cycle $(R F)$ reveals a higher energy saving potential than a conventional cycle with a single loop of serial evaporators, owing to pressure drop in each evaporator during refrigeration operation and low compression ratio. Therefore, several industrial applications and fish storage systems have been utilized by using multipurpose refrigeration cycle. That is why a theoretical performance analysis based on the exergetic performance coefficient, coefficient of performance (COP), exergy efficiency and exergy destruction ratio criteria, has been carried out for a multipurpose refrigeration system by using different refrigerants in serial and parallel operation conditions. The exergetic performance coefficient criterion is defined as the ratio of exergy output to the total exergy destruction rate (or loss rate of availability). According to the results of the study, the refrigerant $\mathrm{R} 32$ shows the best performance in terms of exergetic performance coefficient, COP, exergy efficiency, and exergy destruction ratio from among the other refrigerants (R1234yf, R1234ze, R404A, R407C, R410A, R143A and R502). The effects of the condenser, freezerevaporator and refrigerator-evaporator temperatures on the exergetic performance coefficient, COP, exergy efficiency and exergy destruction ratios have been fully analyzed for the refrigerant $R 32$.
\end{abstract}

Keywords: refrigeration cycles; exergy analysis; exergetic performance coefficient; COP; exergy efficiency;

\section{INTRODUCTION}

Fish is a highly perishable food product because of bacterial and enzymatic activities. Refrigeration reduces these activities and delays spoilage at lower and appropriate temperatures, so fish preservation starts on the vessel as soon as the fish is caught. Conventional refrigeration consisting in pre-cooling with seawater is a low cost refrigeration method but it needs much time and causes to produce relatively high bacterial activities. To prevent that disadvantage, pre-cooling of up to $0 \mathrm{oC}$ done by a multipurpose refrigeration system is proposed [1].

A single vapor-compression cycle that runs at the freezer evaporating saturation temperature supplies both refrigeration and freezer compartments for industrial goods. Even though there are some advantages in space and investment cost when utilizing a single refrigeration cycle, the major reason for the decrease in the overall refrigerator performance originates from lower coefficient of performance (COP) of refrigeration at the freezer temperature, compared to that performed in refrigeration evaporator conditions. Accordingly, the use of two separate cycles to fulfill respective cooling loads for the freezer and the refrigeration compartment results in certain energy savings. Gan, et al. [2] have indicated that the magnitude of the cooling provided to fulfill the refrigeration compartment load triggers large amplification in system performance. The amount of energy savings depends on relative compartment loads. A larger increase in system performance is expected if the majority of cooling is provided to fulfill the refrigeration compartment load.

The advantages in energy saving potential and relative humidity of refrigeration compartments raise the preferability of the two-circuit cycle. Three types of the two-circuit cycle have generally been used as a dual loop cycle with two compressors, a bypass two-circuit cycle, and a two-circuit cycle with parallel evaporators. The investment cost of the dual loop cycle is higher than that of other two circuit cycles (bypass two-circuit cycle and parallel cycle) due to the fact that every cycle has its own compressor, condenser, capillary tube, and evaporator. Yoon et al. [3] have indicated in their experimental study that individual optimization of each loop of a dual loop cycle diminishes energy consumption of the RF compartment. Ding et al [4] have simulated a two-circuit refrigerator-freezer cycle and its application. 
For the bypass two-circuit cycle, there is extremely large temperature difference between the refrigerant and the air in the R-evaporator, due to high compression ratio in the refrigerator operation and large irreversible losses. On the other hand, the employment of a single compressor reduces the initial cost for this cycle. An extra path makes the design and the characteristics of the bypass two-circuit cycle more complicated, as compared to those of the two-evaporator in series cycle and the dual-loop system. In the second part of their study Lu et al. [5] have validated their results with experimental data, and found them compatible. Lavanis et al. [6] and Won et al. [7] have illustrated that the dual loop cycle with a number of smaller compressors and reduced load on each compressor may produce lower efficiency, as a big compressor is more efficient than a small one [3]. Yoon et al. [8] have optimized the dual-loop system based on theoretical analysis and experimental study. Their study pointed out that lowering the compression ratio means a higher energy saving potential of the dual-loop cycle, because of higher evaporating temperature in the refrigerator operation. Bare et al. [9] have indicated that a dual-loop cycle with R-12 has an advantage of $19 \%$ energy saving over the common refrigeration cycle. Also Bare [10] has indicated that the dual-cycle system with refrigerants R142b R152a has a 23\% improvement in overall COP, while the distribution of compartment loads is balanced between the freezer and the fresh food compartments.

The two-circuit cycle with parallel evaporators (called the parallel cycle) for a refrigerator-freezer (RF) eliminates the major drawback of the above mentioned cycles [9]. This significant advantage of the parallel cycle attracts attention of many industrial appliance manufacturers. Yoon et al [11] have studied experimentally the performance of the domestic refrigerator-freezer system and their results indicated higher energy saving potential of the parallel cycle, due to low compression ratio, as the main feature, in combination with high evaporating temperature and low pressure drop in the evaporator during refrigerator operation. Kim et al. [12] and Lavanis et al. [6] have indicated that the parallel cycle has higher efficiency by $2.3 \sim 8.5 \%$ than the two-evaporator cycle in series (serial cycle). On the other hand, Lavanis et al. [6] and Yoon et al. [3] have shown that the refrigerant recovery operation is needed to make adequate flow in the refrigerator operation, which is a source of additional energy consumption, to provide sufficient amount of refrigerant.

Wang and Wang [13] have compared single-stage compression with two-stage compression in the refrigeration cycle. The obtained results show that the COPs of the serial two-stage compression and parallel two-stage compression systems are higher by $2.1 \%$ and $11.6 \%$, respectively, than that of the single stage cycle. Also, the COP of the parallel two-stage system is higher by $9.7 \%$ than that of the serial two-stage system.

Wang and $\mathrm{Yu}$ [14] have presented an experimental study on a novel ejector enhanced refrigeration cycle used in the domestic refrigerator-freezer. They compared the ejector pressure lift ratio and the energy consumption under different combinations of design parameters. Yang et al. [15] have made a parametric analysis of the two-circuit cycle with evaporating subcooler to obtain the highest COP in domestic refrigeratorfreezer systems. Lu and Ding [16] have analyzed two circuit cycles with respect to a new control strategy which based on temperature and time-sharing running combination. Their analyses showed that the refrigerator-freezer cycle with parallel evaporators is more efficient than single-loop and bypass two circuit cycle refrigerator-freezer units.

An "on-off" controlled household refrigerator and freezer system was modeled by Hermes and Melo [17] to simulate transient behavior. It was also experimentally analyzed by Hermes et al. [18] in order to predict energy consumption in steady state conditions. A comparative analysis of different configurations of domestic refrigerators (of top, bottom and side mounted freezer types) was numerically simulated using computational fluid dynamics approach by Esmail and Mokheimer [19]. Sand et al. [20] have presented a numerical and experimental study which compared the basic refrigeration cycle with two evaporator refrigeration systems using different refrigerants and refrigeration cycles. Wisek [21] and Wisek et al. [22] have carried out an experimental study using phase change material concept for a sequential dual evaporator refrigeration system in refrigeration and freezing applications in order to optimize energy consumption and performance parameters. A semi-empirical modeling approach to the household refrigerator model was employed to assess the effect of various system parameters on refrigerator's performance and predicted performance criteria values, compared with experimental data [23].

The exergetic performance coefficient (EPC) is defined as the ratio of exergy output to the total exergy destruction rate. Ust and Karakurt [24] have analyzed the cascade refrigeration system with different refrigerants using the EPC criterion. Their analyses showed that the best EPC rate of the component were obtained for the cascade condenser low-temperature cycle expansion valve, then for the high-temperature cycle expansion valve, the high temperature cycle evaporator, and finally for the low temperature cycle compressor.

The objective of this study is to investigate the theoretical performance of MRS in terms of COP, EPC, exergy efficiency, and exergy destruction ratio. In order to carry out this aim, MRS was first thermodynamically modeled based on mass, energy and exergy balance equations. Using this model, different refrigerants were investigated to find the best refrigerant yielding the highest COP, EPC and exergy efficiency for MRS. Finally, for the selected refrigerant the effects of important parameters, such as condenser temperature and evaporator temperatures, on the performance of the MRS were determined through a parametric study.

\section{THERMODYNAMIC ANALYSIS OF MULTIPURPOSE REFRIGERATOR SYSTEM \\ TWO-CIRCUIT CYCLE WITH SERIAL EVAPORATOR SYSTEM}

The cycle includes two separate evaporators (R-evaporator and F-evaporator), a condenser, a compressor, three expansion 
valves and a three-way valve. The schematic diagram of the irreversible two stage multipurpose refrigerator model and its T-s diagram are given in Fig. $1 \mathrm{a}-\mathrm{b}$. The cycle operates between two heat sources of temperature TR and TF and a heat sink of temperature T0 [25]. The refrigerant flowing into the compressor (state 1) is the saturated vapor and is compressed to the condenser pressure in the vaporcompression refrigeration cycle (state 2 ). The temperature of the refrigerant rises during this isentropic compression above the ambient temperature. Then the refrigerant flows into the condenser, where it becomes the superheated liquid (state 3). The saturated liquid refrigerant coming from the condenser goes to Expansion valve 1 which is throttled to the R-evaporator pressure (state 4). After that the refrigerant goes to F- evaporator. After heat rejection to the environment, the leaving refrigerant becomes wet vapor (state 6). The initial temperature of the refrigerant in both refrigerators is at the level of those in the refrigerated spaces and decreases below them during these processes. The refrigerant part from the F-evaporator becomes the saturated vapor (state 1 ) and reenters the compressor, thus finalizing the cycle.

(a)

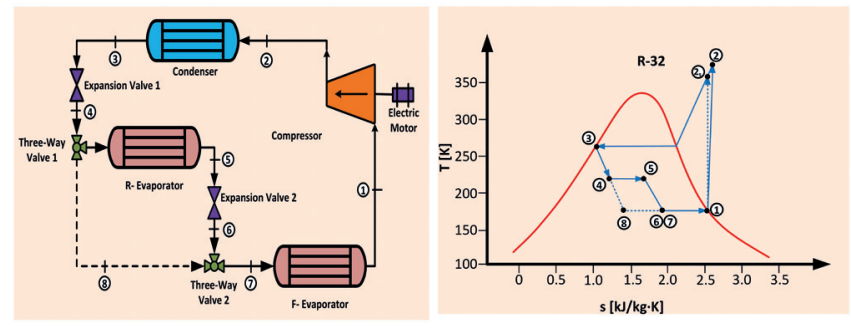

(b)

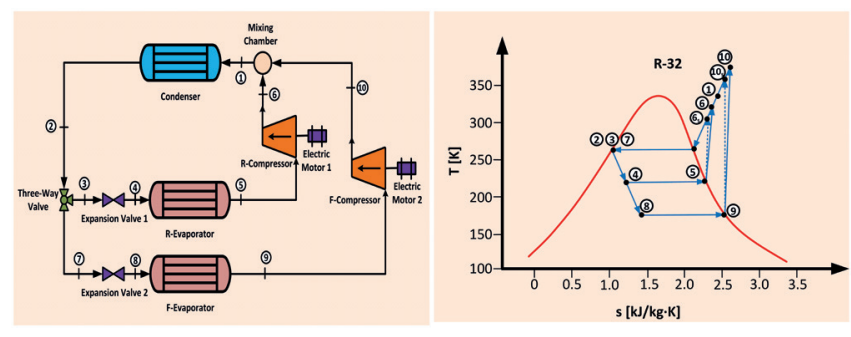

Fig. 1. Schematic diagrams of irreversible MRS and its T-s diagrams.

Two-circuit cycle with parallel evaporators system

This cycle has almost the same equipment as the bypass two-circuit cycle system. Additionally, the parallel cycle has a three-way valve, two separate compressors (R-compressor and F-compressor) and a mixing chamber. The basic difference in operation of the parallel cycle is that the refrigerant leaving R-evaporator does not go to F-evaporator. $\mathrm{R}$-evaporator and F-evaporator are separate cycles. The saturated liquid refrigerant (state 2) goes to the three-way valve, then (states 3 and 7) is throttled to the R-evaporator and F-evaporator pressures by the expansion valve 1 (state 4 ) and expansion valve 2 (state 8). Heat rejection in R-evaporator and F-evaporator makes the refrigerant become the saturated vapor (state 5 and 9). Then the refrigerant from F-evaporator goes to F-compressor and that from R-evaporator goes to
R-compressor. After the compression process, (states 6 and 10) the both refrigerants mix together (state 1) and the cycle finishes.

The rate of heat flow from the heat source to the evaporator $\dot{Q}_{\text {Evap }}$, the rate of heat transfer from the multipurpose condenser, and the rate of heat flow from the condenser to the heat sink $\dot{Q}_{C o n}$ can be written separately as:

$$
\begin{gathered}
\dot{\mathrm{Q}}_{\text {Evap }, \mathrm{R}}=\dot{\mathrm{m}}_{1}\left(\mathrm{~h}_{5}-\mathrm{h}_{4}\right)=\dot{\mathrm{m}}_{\mathrm{f}} \mathrm{C}_{\mathrm{P}, \mathrm{f}}\left(\mathrm{T}_{\mathrm{f}}-\mathrm{T}_{\text {Evap }, \mathrm{R}}\right) \\
\dot{\mathrm{Q}}_{\text {Evap }, \mathrm{F}}=\dot{\mathrm{m}}_{2}\left(\mathrm{~h}_{1}-\mathrm{h}_{6}\right)=\dot{\mathrm{m}}_{\mathrm{f}} \mathrm{C}_{\mathrm{Pf}, \mathrm{f}}\left(\mathrm{T}_{\text {Evap }, \mathrm{R}}-\mathrm{T}_{\text {Evap }, \mathrm{F}}\right)+\dot{\mathrm{m}}_{\mathrm{f}} \mathrm{L}_{\mathrm{f}} \\
\dot{\mathrm{Q}}_{\text {Con }}=\dot{\mathrm{m}}\left(\mathrm{h}_{2}-\mathrm{h}_{3}\right)
\end{gathered}
$$

where $\dot{m}$ is the mass flow rate of the refrigerant $\left(\dot{m}_{1}=\dot{m}_{2}=\dot{m}\right.$ for $\mathrm{MRS}_{\mathrm{S}}$ and $\dot{m}_{1}+\dot{m}_{2}=\dot{m}$ for $\mathrm{MRS}_{\mathrm{p}}$ ) and $\mathrm{h}$ denotes the enthalpy. The electrical power input for the compressor is given as:

$$
\dot{\mathrm{W}}_{\mathrm{Com}}=\frac{\dot{\mathrm{m}}\left(\mathrm{h}_{2}-\mathrm{h}_{1}\right)}{\eta_{\mathrm{m}} \eta_{\mathrm{em}}}
$$

The coefficient of performance (COP) is used as a major performance criterion in general performance analyses of refrigeration systems. The coefficient of performance gives the information about the necessary electrical power input to produce certain magnitude of cooling load. The first law of thermodynamics says that the coefficient of performance is specified as the ratio of cooling load to the electrical power input for the multipurpose refrigeration cycle and is given as below:

$$
\begin{gathered}
\dot{\mathrm{Q}}_{\mathrm{L}}=\dot{\mathrm{Q}}_{\text {Evap }, \mathrm{R}}+\dot{\mathrm{Q}}_{\text {Evap }, \mathrm{F}} \\
\mathrm{COP}=\frac{\dot{\mathrm{Q}}_{\mathrm{L}}}{\dot{\mathrm{W}}_{\mathrm{Com}}}
\end{gathered}
$$

\section{EXERGY DESTRUCTION RATE IN SYSTEM COMPONENTS}

Exergy analysis of the process is an additive to energy analysis. It is used to appreciate work potentials of input and output materials and heat streams, and to determine locations and amounts of irreversibility losses. The exergetic analysis gives significant information about irreversibility distribution among plant's components, specifying which component weighs more on the overall plant inefficiency. In this study, only physical exergy in the system is taken into account, while alterations of kinetic, potential, and chemical exergy are neglected. Physical exergy transformation is provided from thermal and mechanical processes. These equations can be denoted on the basis of their definitions as [26]:

$$
\dot{\mathrm{E}}_{\mathrm{X}}^{\mathrm{PH}}=\dot{\mathrm{m}}_{\mathrm{i}}\left[\left(\mathrm{h}_{\mathrm{i}}-\mathrm{h}_{0}\right)-\mathrm{T}_{0}\left(\mathrm{~s}_{\mathrm{i}}-\mathrm{s}_{0}\right)\right]
$$


where $\dot{m}$ is the mass flow rate, $\mathrm{s}$ is the specific entropy in conditions specified for the species, and the subscript 0 shows ambient conditions. The general exergy balance can be denoted in the rate form as:

$$
\dot{\mathrm{E}}_{\mathrm{X}, \text { in }}=\dot{\mathrm{E}}_{\mathrm{X}, \text { out }}+\dot{\mathrm{E}}_{\mathrm{XD}}
$$

For the control volume of any component of the continual steady state process, the general equation of exergy destruction rate arising from the exergy balance is

$\dot{\mathrm{E}}_{\mathrm{XD}, \mathrm{i}}=\sum\left[\dot{\mathrm{Q}}\left(1-\frac{\mathrm{T}_{0}}{\mathrm{~T}}\right)\right]_{\text {in }}-\sum\left[\dot{\mathrm{Q}}\left(1-\frac{\mathrm{T}_{0}}{\mathrm{~T}}\right)\right]_{\text {out }}+\sum\left[(\dot{\mathrm{W}})_{\text {in }}-(\dot{\mathrm{W}})_{\text {out }}\right]+\sum\left[\left(\dot{\mathrm{E}}_{\mathrm{X}}\right)_{\text {in }}-\left(\dot{\mathrm{E}}_{\mathrm{X}}\right)_{\text {out }}\right]$

where $\dot{\mathrm{E}}_{\mathrm{xD}, \mathrm{i}}$, symbolizes the rate of exergy destruction existing in process components. The first and second terms on the right-hand side of the above equation represent exergy rate transfers by heat and work, separately. $\dot{Q}$ symbolizes the heat transfer rate across the boundary of the system at constant temperature T. $\dot{\mathrm{E}}_{\mathrm{x}}$ is the exergy rate transfer by mass of each substance flow crossing the system boundary.

By regarding Eq. (8), the rates of exergy destruction acquired for each component of MRS are given in Table-1.

Tab. 1. $\dot{\mathrm{E}}_{\mathrm{XD}, \mathrm{Evap}}, \mathrm{EPC}, \varepsilon, \mathrm{y}$ for each component

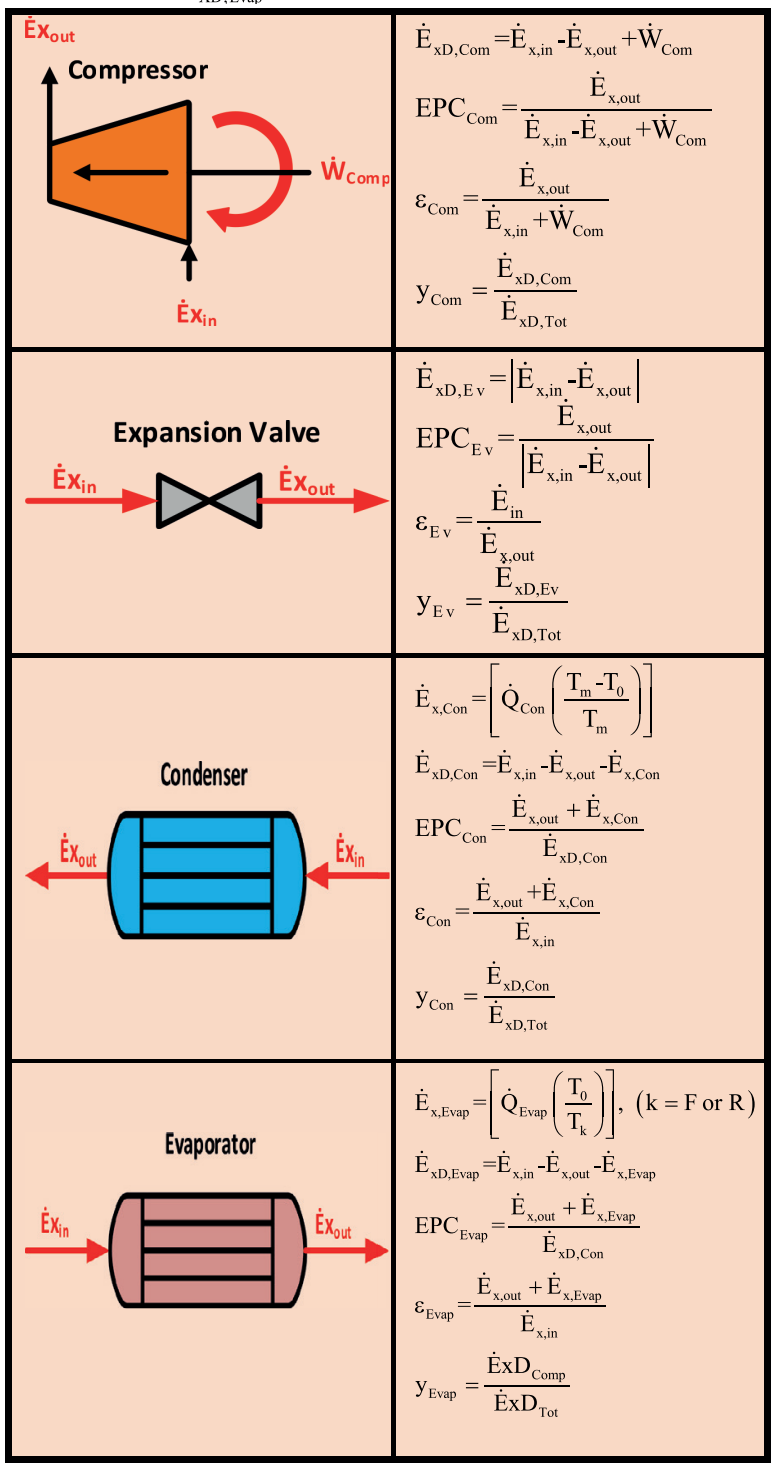

Here $\dot{E}_{X, \dot{Q}_{\text {Con }}}, \dot{E}_{X, \dot{Q}_{\text {vap }, R .}}$ and $\dot{E}_{X, \dot{Q}_{\text {Eup } F}}$ are the thermal exergy rates related with $Q_{\text {Con }, R}, \dot{Q}_{\text {Evap }, R}$ and $Q_{\text {Evap }, F}$ which can be stated separately. The refrigerated space temperature $\left(\mathrm{T}_{\mathrm{R}}\right)$, the frozen space temperature $\left(\mathrm{T}_{\mathrm{F}}\right)$ and the mean temperature $\left(\mathrm{T}_{\mathrm{m}}\right)$ are defined as:

$$
\begin{gathered}
\mathrm{T}_{\mathrm{R}}=\mathrm{T}_{\text {Evap }, \mathrm{R}}+\Delta \mathrm{T} \\
\mathrm{T}_{\mathrm{F}}=\mathrm{T}_{\text {Evap, } \mathrm{F}}+\Delta \mathrm{T} \\
\mathrm{T}_{\mathrm{m}}=\left(\frac{\mathrm{h}_{\text {in }}-\mathrm{h}_{\text {out }}}{\mathrm{s}_{\text {in }}-\mathrm{s}_{\text {out }}}\right)_{\text {Con }}
\end{gathered}
$$

\section{EXERGETIC PERFORMANCE COEFFICIENT}

Getting the information about exergy destructions in MRS requires adopting another performance criterion. Here, the performance criterion bearing the name of exergetic performance coefficient (EPC), previously proposed by Ust [27], is used. The EPC objective function for MRS is defined as the ratio of exergy output to overall exergy destruction. EPC is defined as:

$$
\begin{gathered}
\mathrm{EPC}_{\mathrm{i}}=\frac{\dot{\mathrm{E}}_{\mathrm{X}, \text { out }, \mathrm{i}}}{\dot{\mathrm{E}}_{\mathrm{XD}, \mathrm{i}}}=\frac{\dot{\mathrm{E}}_{\mathrm{X}, \text { in }, \mathrm{i}}}{\dot{\mathrm{E}}_{\mathrm{XD}, \mathrm{i}}}-1 \\
\mathrm{EPC}_{\mathrm{Tot}}=\frac{\dot{\mathrm{E}}_{\mathrm{X}, \text { out }}}{\dot{\mathrm{E}}_{\mathrm{XD}, \text { Tot }}}=\frac{\dot{\mathrm{E}}_{\mathrm{x}, \text { Evap }, \mathrm{F}}+\dot{\mathrm{E}}_{\mathrm{X}, \mathrm{Evap}, \mathrm{R}}}{\dot{\mathrm{E}}_{\mathrm{XD}, \text { Tot }}}
\end{gathered}
$$

\section{EXERGY EFFICIENCY}

The exergy efficiency is the ratio of the exergy leaving the system to that going into the system. It can also be defined as the amount of fuel exergy provided to the system that is found in the product exergy [28].

$$
\varepsilon_{\mathrm{i}}=\frac{\mathrm{E}_{\mathrm{X}, \mathrm{i} \text { out }}}{\mathrm{E}_{\mathrm{X}, \mathrm{i}, \mathrm{in}}}
$$

For MRS, the exergy input is equal to the input of electric power for the compressors,

$$
\begin{gathered}
\mathrm{E}_{\mathrm{X}, \mathrm{in}}=\sum \dot{\mathrm{W}}_{\mathrm{Com}} \\
\varepsilon_{\mathrm{tot}}=\frac{\mathrm{E}_{\mathrm{x}, \mathrm{out}}}{\mathrm{E}_{\mathrm{x}, \mathrm{in}}}
\end{gathered}
$$

\section{EXERGY DESTRUCTION RATIO}

The values of exergy destruction rates provide a thermodynamic measure of system inefficiencies. The exergy destruction ratio is defined as the exergy destruction rate of the component to the total exergy destruction rate [28] 


$$
\mathrm{y}_{\mathrm{i}}=\frac{\dot{\mathrm{E}}_{\mathrm{XD}, \mathrm{i}}}{\dot{\mathrm{E}}_{\mathrm{XD}, \mathrm{Tot}}}
$$

EPC, $\varepsilon$ and $y$ for all system components are specified in Table 1.

\section{RESULTS AND DISCUSSION}

In order to illustrate the results of the analysis of exergetic performance coefficient (EPC), coefficient of performance (COP), exergy efficiency $(\varepsilon)$, and exergy destruction ratio (y) for the serial and parallel multipurpose refrigerator (MRS) system, selected numerical results are presented and discussed. The parameters selected for the base case model of MRS system simulation are given in Table 2 .

Tab. 2. Basic parameters for MRSP simulation

\begin{tabular}{|l|l|l|}
\hline Parameters & Units & Values \\
\hline Ambient temperature $\left(\mathrm{T}_{0}\right)$ & $(\mathrm{K})$ & 298 \\
\hline Ambient pressure $\left(\mathrm{P}_{0}\right)$ & $(\mathrm{kPa})$ & 101.325 \\
\hline Freezer evaporator temperature $\left(\mathrm{T}_{\text {Evap }, \mathrm{F}}\right)$ & $(\mathrm{K})$ & 233.15 \\
\hline Refrigerator evaporator temperature $\left(\mathrm{T}_{\text {Evap }, \mathrm{R}}\right)$ & $(\mathrm{K})$ & 273.15 \\
\hline Condenser temperature $\left(\mathrm{T}_{\mathrm{Con}}\right)$ & $(\mathrm{K})$ & 313.15 \\
\hline Fish \& seawater temperature & $(\mathrm{K})$ & 288.15 \\
\hline $\begin{array}{l}\text { Temperature difference between cold spaces } \\
\text { and evaporators }(\Delta \mathrm{T})\end{array}$ & $(\mathrm{K})$ & 10 \\
\hline Electrical motor efficiency $\left(\eta_{\mathrm{em}}\right)$ & $(\%)$ & 95 \\
\hline Isentropic efficiency $\left(\eta_{\mathrm{is}}\right)$ & $(\%)$ & 85 \\
\hline Mechanical efficiency $\left(\eta_{\mathrm{m}}\right)$ & $(\%)$ & 95 \\
\hline
\end{tabular}

The analysis was performed for the refrigerants R1234yf, R1234ze, R32, R404A, R407C, R410A, R143A, and R502. The thermodynamic analysis of the MRS system based on the following assumptions:

i. The operation of all components is of steady-state nature,

ii. Chemical, kinetic and potential energy and exergy of the components are omitted,

iii. Pressure drops in pipelines are neglected,

iv. Heat transfers from/to the compressor and expansion valve are neglected,

v. Expansion of refrigerants in expansion valves is isenthalpic.

vi. Specific heat capacities $\left(\mathrm{C}_{\mathrm{p}}\right)$ are assumed to be constant for refrigeration $(3 \mathrm{kj} / \mathrm{kg} . \mathrm{K})$ and freezing processes (1.65 kj/kg.K)

vii. Refrigerated and frozen fish flow rate is $0.1736 \mathrm{~kg} / \mathrm{s}$ (15 tons/day).
In addition to this, other factors such as environmental effects, and toxicity and flammability characteristics, were also taken into account. Thermo-physical properties of the refrigerants are given in Table 3.

Tab. 3. Refrigerant Properties [29]

\begin{tabular}{|l|l|l|l|l|l|}
\hline Refrigerant & $\begin{array}{l}\text { Boiling } \\
\text { Temp. }\left({ }^{\circ} \mathbf{C}\right)\end{array}$ & $\begin{array}{l}\text { Critical } \\
\text { Temp. }\left({ }^{\circ} \mathbf{C}\right)\end{array}$ & $\begin{array}{l}\text { Critical } \\
\text { Press. (kPa) }\end{array}$ & $\begin{array}{l}\text { Safety } \\
\text { Group }\end{array}$ & ODP \\
\hline R-32 & -52 & 78.11 & 5782 & A2L & 0 \\
\hline R-404A & $-46.6 /-45.8$ & 72.14 & 3735 & A1 & 0 \\
\hline R-407C & $-43.8 /-36.7$ & 86.05 & 4634 & A1 & 0 \\
\hline R-410A & $-51.6 /-51.5$ & 70.17 & 4770 & A1 & 0 \\
\hline R-143a & -47.6 & 72.89 & 3776 & A2L & 0 \\
\hline R-502 & $-45 / 19$ & 80.73 & 4019 & A1 & 0.249 \\
\hline R-1234yf & -29.4 & - & - & A2L & 0 \\
\hline R-1234ze & -19 & - & - & A2L & 0 \\
\hline
\end{tabular}

Variations of EPC, COP and $\varepsilon$ objective functions of MRS for different refrigerants with respect to serial and parallel operation conditions are demonstrated in Fig. 2. We can observe in Fig.2 that R32 gives the maximum EPC, COP and $\varepsilon$ among all other refrigerants. It can also be seen in Fig. 2 that for all refrigerants the objective functions $\mathrm{COP}$ and $\varepsilon$ take always higher values for parallel working conditions than for serial working conditions, while the objective function EPC is higher for serial working conditions than for parallel working conditions. Variations of Atmospheric lifetime (AL), immediately dangerous to life or health (IDLH), and global warming potential (GWP) values for different refrigerants are shown in Fig. 3. Although the R1234 group refrigerants have the lowest GWP, AL and IDLH, the refrigerant R32 alone is most suitable in terms of performance characteristics. Figure 4 shows the EPC and COP objective functions of MRS versus $\mathrm{T}_{\text {Evap, } \mathrm{F}} \mathrm{T}_{\text {Evap, } \mathrm{R}}$ and $\mathrm{T}_{\text {Con }}$ for the refrigerant R32. From Fig. 4 one can conclude that the total EPC objective function decreases for increasing $\mathrm{T}_{\text {Evap, } \mathrm{F}}$ and $\mathrm{T}_{\mathrm{Con}}$, and increases for increasing $\mathrm{T}_{\text {Evap, },}$. The COP value is also decreasing for increasing $\mathrm{T}_{\mathrm{Evap}, \mathrm{R}}$ and $\mathrm{T}_{\text {Con }}$ while increasing for increasing $\mathrm{T}_{\text {Evap, }}$. Variations of EPC with respect to COP as functions of the $T_{\text {Evap, },}, T_{\text {Evap }, R}$ and $\mathrm{T}_{\text {Con }}$ can be seen in Fig. 5 altogether. The EPC objective function decreases for increasing COP by changing $\mathrm{T}_{\mathrm{Evap}, \mathrm{F}}$ and $\mathrm{T}_{\text {Evap, }}$ and it increases by changing $\mathrm{T}_{\text {Con }}$. The effects of $\mathrm{T}_{\mathrm{Evap}, \mathrm{F}}$, $\mathrm{T}_{\text {Evap, } \mathrm{R}}$ and $\mathrm{T}_{\text {Con }}$ on the total exergy efficiency and the exergy efficiency of system components for the parallel MRS and the refrigerant R32 are presented in Fig. 6. The total exergy efficiency increases for increasing $\mathrm{T}_{\text {Evap, } \mathrm{F}}$ and decreases for increasing $\mathrm{T}_{\mathrm{Evap}, \mathrm{R}}$ and $\mathrm{T}_{\text {Con }}$. The exergy efficiencies ordered from highest to lowest are as follows: expansion valve-1, compressor-F, compressor-R and evaporator-R. Variations of the exergetic performance coefficient and exergy destruction ratio of system components for the parallel MRS and R32 with respect to $\mathrm{T}_{\text {Evap, } \mathrm{F}}, \mathrm{T}_{\mathrm{Evap}, \mathrm{R}}$ and $\mathrm{T}_{\text {Con }}$ are pictured in Fig.7 and Fig.8. These figures are important to see the effects of system parameters on exergy destruction ratios and exergetic performance coefficients of particular components for the refrigerant R32. The exergy destruction ratios ordered from 
highest to lowest are as follows: compressor-F, condenser, expansion valve-2, and compressor-R. It can also be seen in Fig. 8 and Table 5 that the best component from the viewpoint of EPC is expansion valve- 1 followed by evaporator- $\mathrm{R}$, expansion valve-2, and evaporator-F. The calculated thermodynamic properties for each node of $\mathrm{R} 32$ refrigeration and the base case exergetic performance of the parallel MRS system and its components are given in Table 4 and 5, respectively. In Table 5, it can be seen that the highest exergy destruction rates in the system occur in the freezer-compressor, then in the condenser and the expansion valve-2, as a result of electrical, mechanical and isentropic efficiencies of the compressor. As the highest irreversibility rate, amounting to much more than half of the total exergy destruction rate, is observed in the compressor, much attention should be given to selecting a freezer compressor for the multipurpose refrigeration system.

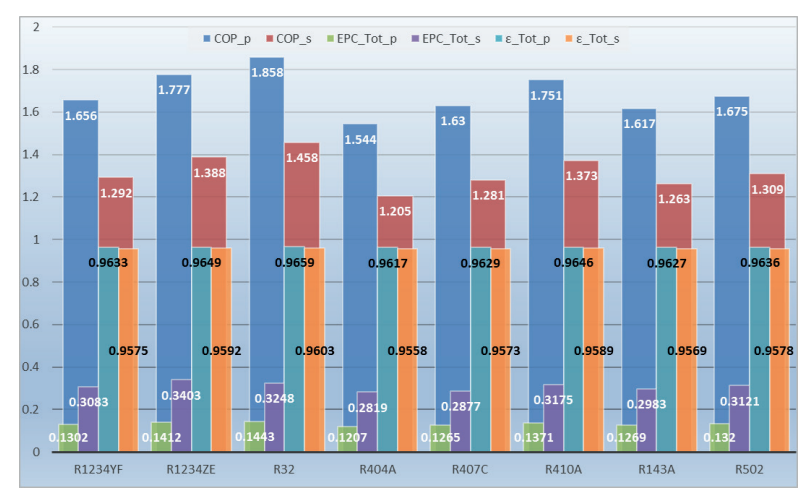

Fig. 2. Variations of COP, EPC \& $\varepsilon$ objective functions of MRSs and MRSP for different refrigerants

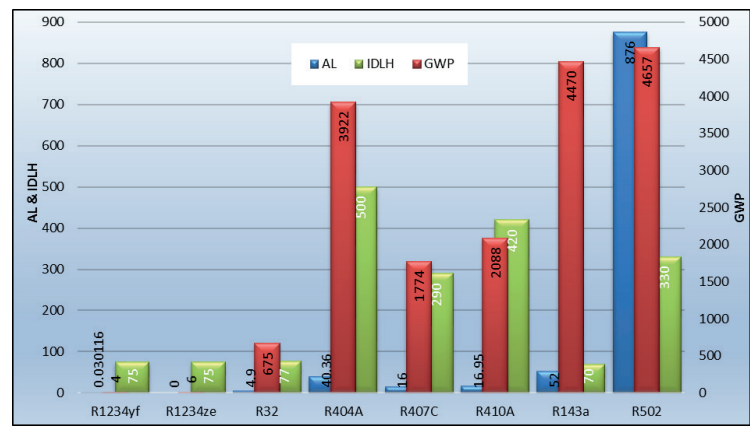

Fig.3. Variations of AL, IDLH \& GWP values of MRSP for different refrigerants

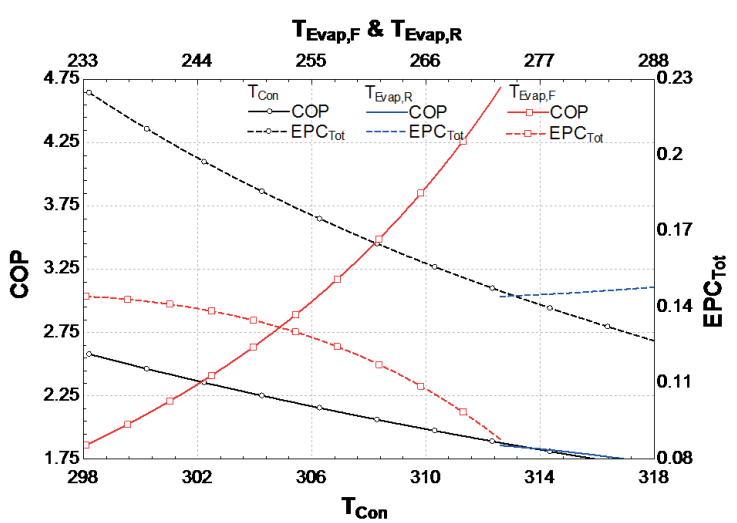

Fig. 4. Variations of COP \& EPC objective functions of MRSP for R32 with respect to $T_{\text {EvapP }} T_{\text {EvapR }}$ and $T_{\text {Con }}$

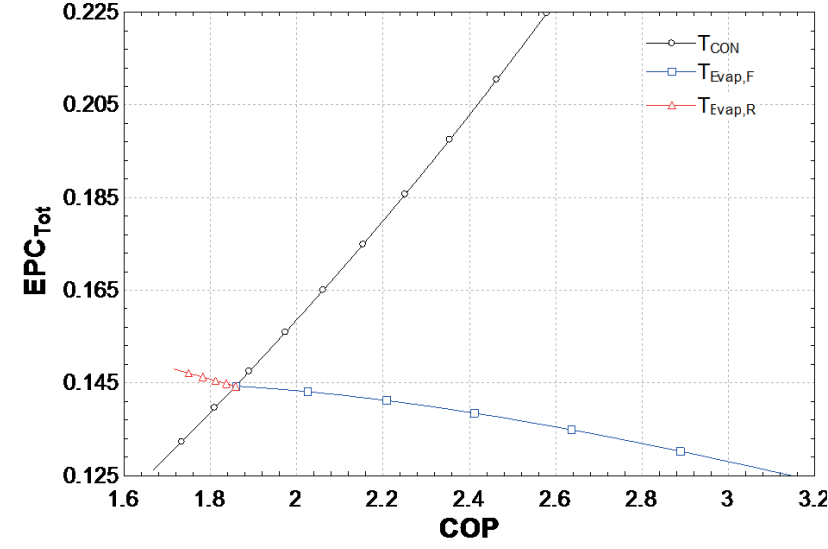

Fig. 5. Variations of EPC with respect to COP as functions of $T_{\text {EvapP }} T_{\text {EvapR }}$ and $T_{\text {Con }}$ for $R 32$

(a)

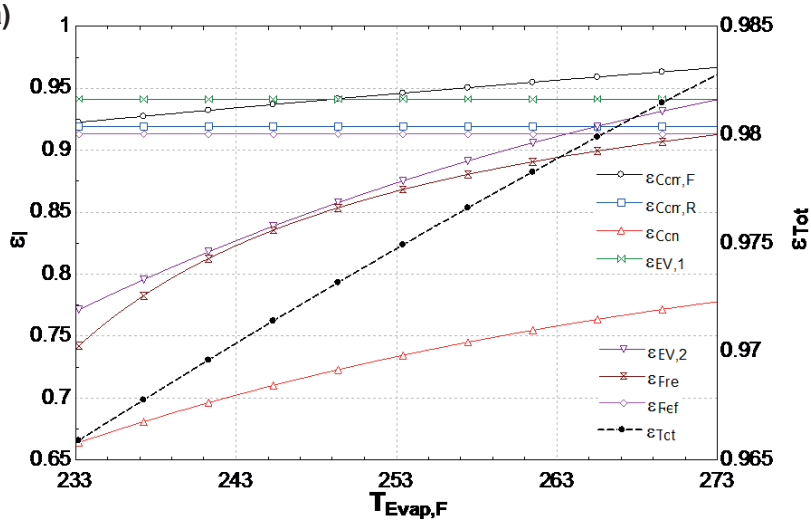

(b)

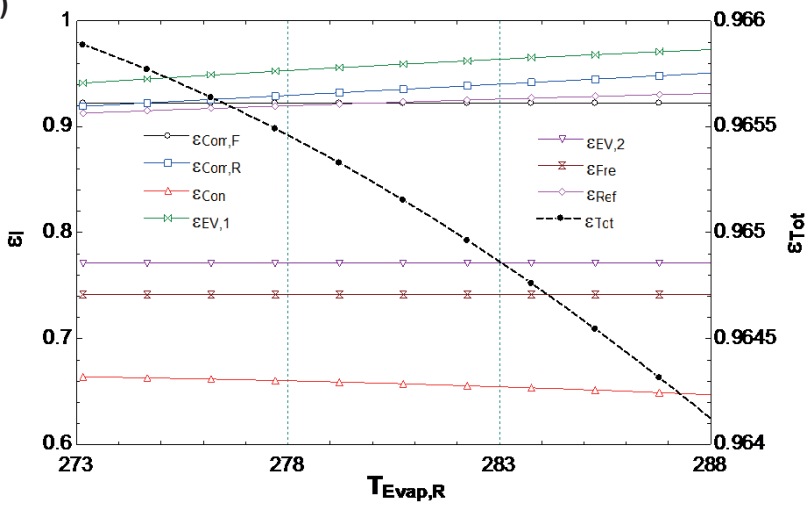

(c)

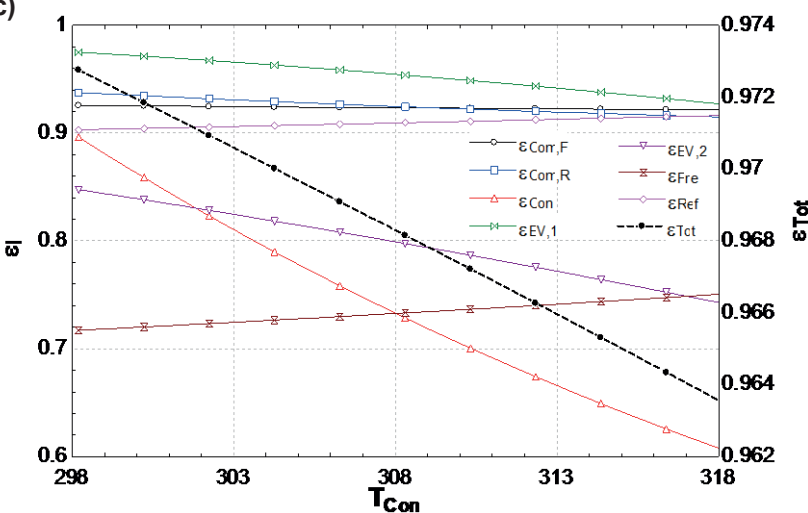

Fig. 6. Variations of exergetic efficiency of MRSP and its components for R32 with respect to a) $T_{\text {Evap }}$; b) $T_{\text {EvapR }}$; and c) $T_{\text {Con }}$ 


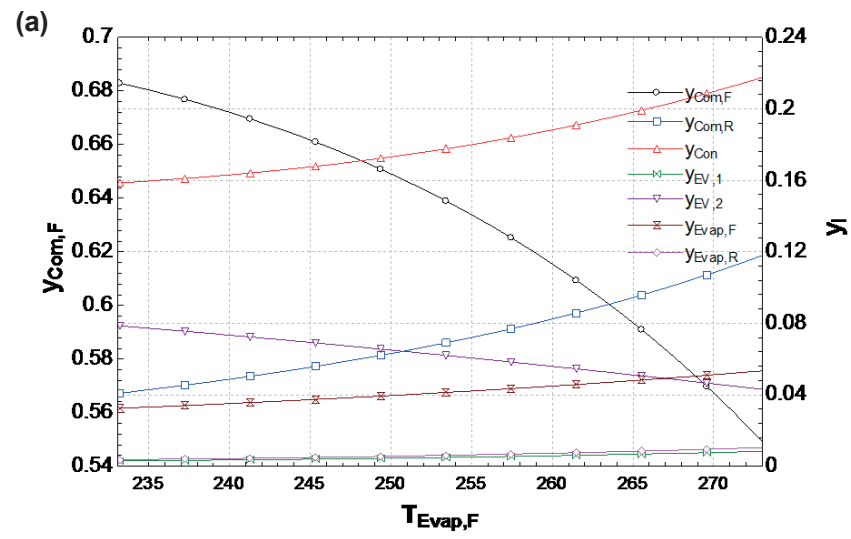

(b)

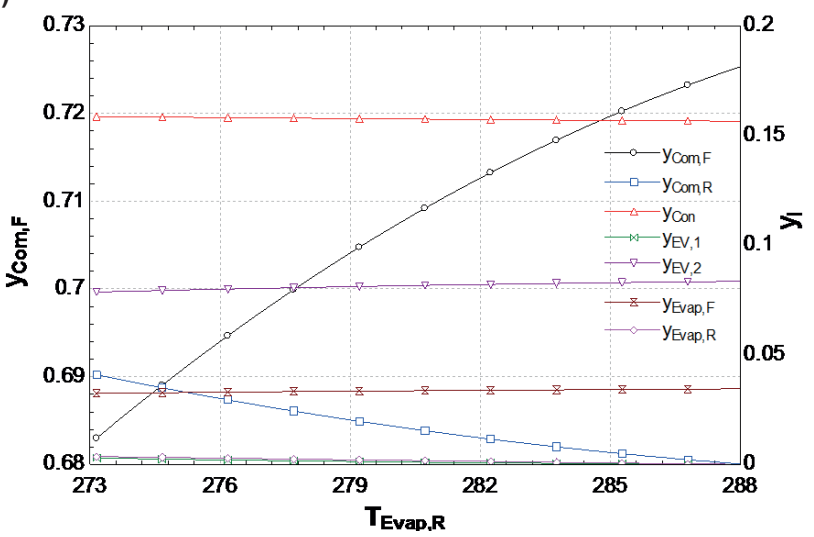

(c)

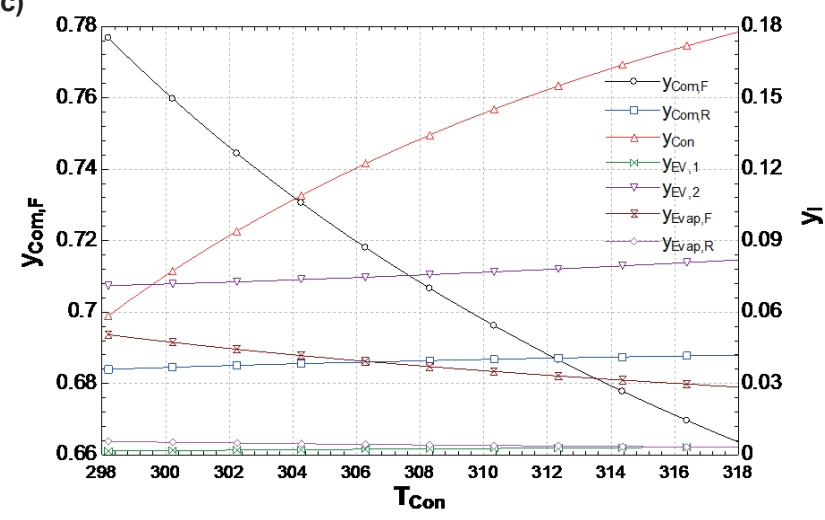

Figure 7. Variations of exergy destruction rate of MRSP components for R32 with respect to a) $T_{\text {Evapp }}$ b) $T_{\text {EvapR }}$; and c) $T_{\text {Con }}$

Table 4-Base case simulation results at each node of MRSP for R32

\begin{tabular}{|l|l|l|l|l|l|l|}
\hline Node & $\boldsymbol{P}(\boldsymbol{b a r})$ & $\boldsymbol{T}(\boldsymbol{K})$ & $\boldsymbol{x}$ & $\boldsymbol{h}(\boldsymbol{k J} / \mathbf{k g})$ & $\boldsymbol{s}(\boldsymbol{k J} /(\mathbf{k g} \boldsymbol{K})$ & $\boldsymbol{E}_{\boldsymbol{x}}(\boldsymbol{k W})$ \\
\hline 1 & 24.78 & 393.6 & & 621.1 & 2.32 & 41.74 \\
\hline 2 & 24.78 & 387.9 & & 614.5 & 2.303 & 47.25 \\
\hline 3 & 24.78 & 313.2 & 0 & 275.6 & 1.252 & 39.31 \\
\hline 4 & 24.78 & 313.2 & 0 & 275.6 & 1.252 & 4.936 \\
\hline 5 & 8.132 & 273.2 & 0.2398 & 275.6 & 1.277 & 4.646 \\
\hline 6 & 8.132 & 273.2 & 1 & 515.3 & 2.154 & 3.788 \\
\hline 7 & 24.78 & 349.8 & & 568.1 & 2.177 & 5.588 \\
\hline 8 & 24.78 & 313.2 & & 275.6 & 1.252 & 34.37 \\
\hline 9 & 1.774 & 233.2 & 0.3861 & 275.6 & 1.349 & 26.5 \\
\hline 10 & 1.774 & 233.2 & 1 & 502 & 2.32 & 9.307 \\
\hline
\end{tabular}
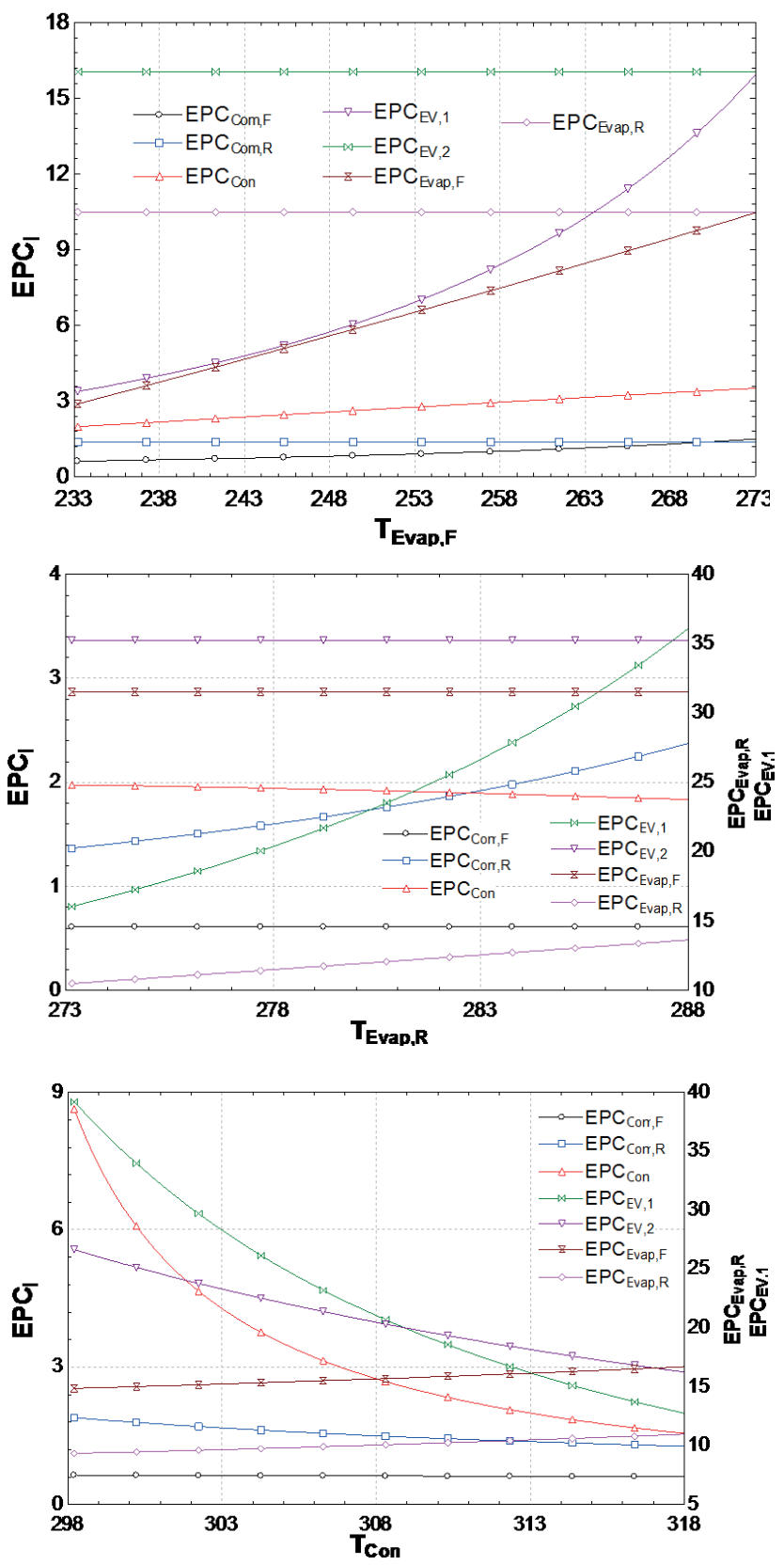

Fig. 8. Variations of EPC of MRSP components for $R 32$ with respect to a) $T_{\text {Evapp }}$ b) $T_{\text {EvapR }}$ and c) $T_{\text {Con }}$

Tab. 5. Base case exergetic performance results of MRSP and its components for R32

\begin{tabular}{|l|l|l|l|l|}
\hline $\begin{array}{l}\text { System } \\
\text { Components }\end{array}$ & $\varepsilon$ & $\boldsymbol{E P C}$ & $\boldsymbol{y}$ & $\begin{array}{l}\boldsymbol{E x D} \\
(\boldsymbol{k W})\end{array}$ \\
\hline Compressor_F & 0.9226 & 0.6105 & 0.683 & 68.38 \\
\hline Compressor_R & 0.9194 & 1.366 & 0.04085 & 4.09 \\
\hline Condenser & 0.6639 & 1.975 & 0.1586 & 15.88 \\
\hline Exp. Valve_1 & 0.9413 & 16.04 & 0.00289 & 0.2896 \\
\hline Exp. Valve_2 & 0.771 & 3.367 & 0.07862 & 7.871 \\
\hline Evap. Freezer & 0.7415 & 2.869 & 0.0324 & 3.244 \\
\hline Evap. Refriger. & 0.9129 & 10.48 & 0.0036 & 0.3613 \\
\hline Total & 0.9659 & 0.1443 & 1 & 100.1 \\
\hline
\end{tabular}




\section{CONCLUSION}

Performance evaluation of the multipurpose refrigeration system by using such parameters as exergetic performance coefficient, exergy efficiency, coefficient of performance, and exergy destruction ratio as performance criteria has been carried out in order to provide guidance for the conceptual design of MRS. From the definition of EPC function, it represents a compromise between exergy output and total exergy destruction rate in view of environmental considerations. This thermodynamic analysis has been carried out using different refrigerants based on given conditions. The main results are outlined as below:

- $\quad$ Although R1234yf and R1234ze have the lowest GWP, AL and IDLH, the refrigerant R32 shows the best performance in terms of EPC, COP and $\varepsilon$ objective functions.

- $\quad$ Parallel operation of MRS gives better performance in terms of COP and $\varepsilon$ than serial operation of MRS while EPC performance is opposite for all refrigerants.

- Total exergy efficiency decreases with increasing $\mathrm{T}_{\text {Evap, } \mathrm{R}}$ and $\mathrm{T}_{\mathrm{Con}}$ and increases with increasing $\mathrm{T}_{\text {Evap, } \mathrm{F}}$

- The best component from the viewpoint of EPC is expansion valve-1 followed by evaporator- $\mathrm{R}$, expansion valve-2, and evaporator-F.

- The exergy efficiencies ordered from highest to lowest are as follows: expansion valve-1, compressor-F, compressor- $\mathrm{R}$ and evaporator- $\mathrm{R}$ from.

- The exergy destruction ratios ordered from highest to lowest are as follows: compressor-F, condenser, expansion valve- 2 and compressor-R.

- The method presented in the paper can also be applied to other refrigerants and working cycles.

\section{REFERENCES}

1. Y. A. Çengel, Heat and Mass Transfer: A Practical Approach, 3rd ed. Online: McGraw-Hill Higher Education, 2007.

2. A. I. Gan, S. A. Klein, and D. T. Reindl, "Analysis of Refrigerator / Freezer Appliances Having Dual Refrigeration Cycles," Ashrae Trans., vol. 106, no. 2, pp. 1-7, 2000.

3. W. J. Yoon, H. W. Jung, H. J. Chung, and Y. Kim, "Performance optimization of a two-circuit cycle with parallel evaporators for a domestic refrigerator-freezer," Int. J. Refrig., vol. 34, no. 1, pp. 216-224, Jan. 2011.

4. G. Ding, C. Zhang, and Z. Lu, "Dynamic simulation of natural convection bypass two-circuit cycle refrigeratorfreezer and its application: Part I: Component models," Appl. Therm. Eng., vol. 24, no. 10, pp. 1513-1524, Jul. 2004.

5. Z. Lu, G. Ding, and C. Zhang, "Dynamic simulation of natural convection bypass two-circuit cycle refrigeratorfreezer and its application: Part II: System simulation and application," Appl. Therm. Eng., vol. 24, no. 10, pp. 1525-1533, Jul. 2004.
6. M. Lavanis, I. Haider, and R. Radermacher, "Experimental investigation of an alternating evaporator duty refrigerator/ freezer," presented at the ASHRAE Transactions, Toronto, 1998, vol. 104.

7. S. Won, D. Jung, and R. Radermacher, "An experimental study of the performance of a dual-loop refrigerator freezer system," Int. J. Refrig., vol. 17, no. 6, pp. 411-416, Jul. 1994.

8. W. J. Yoon, K. Seo, H. J. Chung, and Y. Kim, "Performance optimization of dual-loop cycles using R-600a and hydrocarbon mixtures designed for a domestic refrigeratorfreezer," Int. J. Refrig., vol. 35, no. 6, pp. 1657-1667, Sep. 2012.

9. J. C. Bare, C. L. Gage, R. R, and J. D.S., "Simulation of nonazeotropic refrigerant mixtures for use in a dual-circuit refrigerator/freezer with countercurrent heat exchanges," 1991.

10. J. C. Bare, "Simulation Results of Single Refrigerants for Use in Dual-Circuit Refrigerator/Freezer," J. Air Waste Manag. Assoc., vol. 42, no. 2, pp. 185-186, 1992.

11. W. J. Yoon, H. W. Jung, H. J. Chung, and Y. Kim, “An Experimental Study on the Performance of a Two Circuit Cycle with Parallel Evaporators for a Domestic Refrigerator-Freezer."

12. K. Kim, B. Kopko, and R. Radermacher, "Application of tandem system to high-efficiency refrigerator/freezer," presented at the ASHRAE Transactions, 1995, vol. 101, p. 2.

13. Y. Joo, Y. Kim, M. Lee, W. Yoon, and Y. Kim, "Performance Characteristics of a Household Refrigerator with Dual Evaporators Using Two-Stage Compression Cycle," Int. J. Air-Cond. Refrig., vol. 17, no. 3, pp. 107-113, 2009.

14. X. Wang and J. Yu, "An experimental investigation on a novel ejector enhanced refrigeration cycle applied in the domestic refrigerator-freezer," Energy, vol. 93, Part 1, pp. 202-209, Dec. 2015.

15. M. Yang, C. W. Jung, and Y. T. Kang, "Development of high efficiency cycles for domestic refrigerator-freezer application," Energy, vol. 93, Part 2, pp. 2258-2266, Dec. 2015.

16. Z. Lu and G. Ding, "Temperature and time-sharing running combination control strategy of two-circuit cycle refrigerator-freezer with parallel evaporators," Appl. Therm. Eng., vol. 26, no. 11-12, pp. 1208-1217, Aug. 2006.

17. C. J. L. Hermes and C. Melo, "A first-principles simulation model for the start-up and cycling transients of household refrigerators," Int. J. Refrig., vol. 31, no. 8, pp. 1341-1357, Dec. 2008. 
18. C. J. L. Hermes, C. Melo, F. T. Knabben, and J. M. Gonçalves, "Prediction of the energy consumption of household refrigerators and freezers via steady-state simulation," Appl. Energy, vol. 86, no. 7-8, pp. 1311-1319, Jul. 2009.

19. Y. S. S. Esmail M. A. Mokheimer, "Comparative Analysis of Different Configuration Domestic Refrigerators: A Computational Fluid Dynamics Approach,” J. Energy Resour. Technol., vol. 137, no. 6, p. 062002, 2015.

20. J. R. Sand, C. L. Rice, and E. A. Vineyard, "Alternative Refrigerants and Refrigeration Cycles for Domestic Refrigerators," Oak Ridge National Lab., TN (United States), ORNL/M--2270, Dec. 1992.

21. M. VISEK, "Study of innovative techniques aimed at reducing energy consumption in domestic refrigeration system," 05-Mar-2013. Available: https://www.politesi. polimi.it/handle/10589/74911.

22. M. Visek, C. M. Joppolo, L. Molinaroli, and A. Olivani, "Advanced sequential dual evaporator domestic refrigerator/ freezer: System energy optimization,” Int. J. Refrig., vol. 43, pp. 71-79, Jul. 2014.

23. J. M. Gonçalves, C. Melo, and C. J. L. Hermes, "A semiempirical model for steady-state simulation of household refrigerators," Appl. Therm. Eng., vol. 29, no. 8-9, pp. 1622-1630, Jun. 2009.

24. Y. Üst and A. S. Karakurt, "Analysis of a Cascade Refrigeration System (CRS) by Using Different Refrigerant Couples Based on the Exergetic Performance Coefficient (EPC) Criterion,” Arab. J. Sci. Eng., vol. 39, no. 11, pp. 8147-8156, Nov. 2014

25. Yunus A. Çengel and Michael A. Boles, Thermodynamics An Angineering Approach, 5th ed. McGraw-Hill Higher Education, 2006.

26. T. J. Kotas, The exergy method of thermal plant analysis. Butterworths, 1985.

27. Y. Ust, A. V. Akkaya, and A. Safa, "Analysis of a vapour compression refrigeration system via exergetic performance coefficient criterion," J. Energy Inst., vol. 84, no. 2, pp. 66-72, May 2011.

28. A. Bejan and M. J. Moran, Thermal Design and Optimization. John Wiley \& Sons, 1996.

29. "ASHRAE Handbook-Fundamentals," in Designation and safety classification of refrigerants, ASHRAE, 2007, pp. $8-12$.

\section{CONTACT WITHE THE AUTHOR}

\author{
Yasin Ust \\ Department of Naval Architecture \\ Yildiz Technical University \\ Besiktas 34349 \\ Istanbul \\ Turkey
}

Tel.: +90-212-383-2980;

fax: $+90-212-383-2989$.

E-mail address: yust@yildiz.edu.tr 